\title{
Rochalimaea elizabethae sp. nov. Isolated from a Patient with Endocarditis
}

\author{
JENNIFER S. DALY, ${ }^{1 *}$ MICHAEL G. WORTHINGTON, ${ }^{2}$ DON J. BRENNER ${ }^{3}$ C. WAYNE MOSS, ${ }^{3}$ \\ DANNIE G. HOLLIS, ${ }^{3}$ ROBBIN S. WEYANT, ${ }^{3}$ ARNOLD G. STEIGERWALT, ${ }^{3}$ ROBERT E. WEAVER, ${ }^{3}$ \\ M. I. DANESHVAR, ${ }^{3}$ AND STEVEN P. O'CONNOR ${ }^{4}$ \\ The Medical Center of Central Massachusetts, University of Massachusetts Medical School, Worcester, \\ Massachusetts $01605^{1}$; Saint Elizabeth's Hospital, Tufts University School of Medicine, Brighton, \\ Massachusetts 021352; and Meningitis and Special Pathogens Branch ${ }^{3}$ and Respiratory Diseases Branch, ${ }^{4}$ \\ Division of Bacterial and Mycotic Diseases, National Center for Infectious Diseases, Centers for \\ Disease Control and Prevention, Atlanta, Georgia 30333
}

Received 28 September 1992/Accepted 30 December 1992

\begin{abstract}
A Rochalimaea-like organism (strain F9251) was isolated from a patient with endocarditis after blood drawn for culture before antimicrobial therapy was subcultured onto blood and chocolate agars and incubated for 2 weeks in $5 \% \mathrm{CO}_{2}$. The strain was phenotypically similar to known Rochalimaea species. The cellular fatty acid composition of strain $\mathbf{F 9 2 5 1}$ was close to but distinct from those of the three known Rochalimaea species and was most similar to that of $R$. vinsonii. Labeled DNA from strain F9251 was 59 to $67 \%$ related to DNAs from type strains of the three described Rochalimaea species, and its 16S rRNA gene sequence was 98.9\% or more homologous to their 16S rRNA gene sequences. These findings support classification of F9251 as a new Rochalimaea species, for which the name Rochalimaea elizabethae sp. nov. is proposed. The patient infected with the organism had large bacterial vegetations on his aortic valve and was cured with antibiotics and valve-replacement surgery. Recognition of the procedures required to identify this and other Rochalimaea species suggests that clinical laboratories should prolong the incubation times of cultures of blood and tissue from patients with suspected endocarditis, patients with fever of unknown origin, and immunocompromised patients with fever so that the full spectrum of disease caused by these organisms can be recognized.
\end{abstract}

Three Rochalimaea species (family Rickettsiaceae) have been described. $R$. quintana, the type species and causative agent of trench fever, was originally termed "Rickettsia quintana" by Schmincke in 1917 (35), but the organism was transferred to the genus Rochalimaea by Krieg (20) in 1961. The second species, originally referred to as the Canadian vole agent (2), was formally described in 1982 and was named $R$. vinsonii (50). $R$. vinsonii has been isolated only once, from voles on Grosse Isle, Quebec, Canada $(2,51)$. The third Rochalimaea species, $R$. henselae $(28,52)$, was first isolated by Slater, Welch, and coworkers $(37,52)$ and was first detected by Relman and colleagues (32) in tissue samples from patients with bacillary angiomatosis. This organism has been isolated from the blood of patients infected with the human immunodeficiency virus (HIV), transplant recipients, immunocompetent patients with bacteremia, and a patient with peliosis hepatis (52). Relman et al. (33) demonstrated that the rRNA sequences of isolates detected in the blood and organisms detected in the tissues of patients with bacillary angiomatosis represented the same species. By direct cultivation of cutaneous and osseous biopsy specimens with eukaryotic tissue culture endothelial cells, Koehler and coworkers (18) have isolated $R$. henselae from one patient and $R$. quintana from three patients with bacillary angiomatosis, suggesting an etiologic role for both species. Organisms were also recovered from the blood of these patients, but no cases of endocarditis caused by Rochalimaea species have been reported.

In 1986, we isolated an unidentifiable, fastidious organism from a patient with endocarditis. The organism was reexam-

\footnotetext{
* Corresponding author.
}

ined in 1992 after the microbiological and molecular characteristics of $R$. henselae were reported $(28,52)$ and was found to be a fourth species of Rochalimaea. We describe the patient with endocarditis from whom this organism was isolated and propose designation of the bacillus as a new species, Rochalimaea elizabethae sp. nov.

\section{MATERIALS AND METHODS}

Strains. $R$. quintana type strain ATCC VR-358 and $R$. vinsonii type strain ATCC VR-152, which were obtained from the American Type Culture Collection, were provided by Ted Tzianabos, Viral and Rickettsial Zoonoses Branch, Division of Viral and Rickettsial Diseases, National Center for Infectious Diseases, Centers for Disease Control and Prevention (CDC). $R$. henselae type strain ATCC 49882 (Houston 1) was sent to CDC for identification by the Veterans Administration Hospital in Houston, Tex., and was obtained from R. L. Regnery, Viral and Rickettsial Zoonoses Branch, CDC. $R$. henselae 87-66, 88-712, 89-674, and $90-615$ were obtained from David F. Welch, University of Oklahoma Health Sciences Center, Oklahoma City, and have been described previously (52). The type strain of Bartonella bacilliformis, ATCC 35685, has also been described (7). Strain F9251 (=B-91-002005 = ATCC 49927) was sent to CDC by the Massachusetts State Laboratory Institute, which received it from Saint Elizabeth's Hospital in Brighton, Mass.

Primary isolation. Blood obtained from the patient before the start of antimicrobial therapy was inoculated into BACTEC 460 blood culture medium (Johnson Laboratories, Towson, Md.). One bottle was vented for recovery of aerobes, and one was kept closed to allow anaerobic growth. 
The bottles were incubated at $35^{\circ} \mathrm{C}$ for 3 weeks and were then stored at room temperature. When the cultures had not yielded any visible growth at 1 week, subcultures $(0.1 \mathrm{ml})$ from an aerobic bottle were made to tryptic soy agar (TSA) supplemented with 5\% sheep blood (sheep blood-TSA; BBL Microbiology Systems, Cockeysville, Md.) and chocolate agar (BBL), as well as to sheep blood-TSA streaked with Staphylococcus aureus. Incubation was done at $35^{\circ} \mathrm{C}$ in $5 \%$ $\mathrm{CO}_{2}$.

After 3 weeks, samples from both the aerobic and anaerobic bottles were subcultured on chocolate agar, sheep blood-TSA, Campy BAP plate (BBL), Thayer-Martin plate (BBL), and brain heart infusion agar with $5 \%$ sheep blood (BBL). The plates were incubated at $35^{\circ} \mathrm{C}$ in air, in 5 to $10 \%$ $\mathrm{CO}_{2}$ (Campy pouch bags; BBL), anaerobically (GasPak pouch; $\mathrm{BBL}$ ), and at $42^{\circ} \mathrm{C}$ in 5 to $10 \% \mathrm{CO}_{2}$. Once isolated, Rochalimaea-like strain F9251 was cultivated on chocolate agar for phenotypic tests. The organism was stored at $-70^{\circ} \mathrm{C}$ in semisolid heart infusion agar (HIA) or in defibrinated whole rabbit blood.

Samples of blood drawn after the antimicrobial therapy was begun were inoculated into BACTEC 660-NR 6A, 7A, and 16B (resin) bottles (Becton Dickinson and Co., Paramus, N.J.) and were processed with the BACTEC 660-NR system. At the time of the patient's valve-replacement surgery, tissue from his aortic valve was ground and inoculated onto standard media, including thioglycolate and chopped meat broth. The cultures were maintained for 21 days.

Biochemical tests. For the initial biochemical tests we used standard methods (21). Preformed enzymes were tested by using the RapID ANA II system according to the manufacturer's directions (Innovative Diagnostic Systems, Inc., Atlanta, Ga.). Gram staining and biochemical tests were done as described previously (10). The strains were stored in defibrinated rabbit blood in a vapor-phase liquid nitrogen freezer. Inocula for biochemical evaluations were obtained by growing strains on HIA supplemented with $5 \%$ rabbit blood (rabbit blood-HIA; BBL) or on chocolate agar for 2 to 3 days at $35^{\circ} \mathrm{C}$ in candle extinction jars. Cells suspended in heart infusion broth were observed for motility with an oil immersion $(\times 1,000)$ objective.

Antibiotic susceptibility. Antibiotic susceptibility was determined by use of the disk method of Bauer and associates (3). Colonies from a chocolate agar plate incubated for $96 \mathrm{~h}$ were suspended in Mueller-Hinton broth (BBL) and were used to inoculate a chocolate agar plate (BBL). Standard antibiotic-containing disks (BBL) were dropped on the plates, which were incubated for 5 days in $5 \% \mathrm{CO}_{2}$. The clear zone around each disk was measured to the nearest millimeter.

Cellular fatty acids (CFAs). Cells for fatty acid analysis were grown on rabbit blood-HIA at $35^{\circ} \mathrm{C}$ for 2 to 5 days. The cells were saponified, and the liberated fatty acids were methylated and analyzed by capillary gas-liquid chromatography (23). Identification of fatty acids and determination of the locations of double bond positions in monounsaturated acids were accomplished by gas-liquid chromatography and gas-liquid chromatography-mass spectrometry (23).

DNA methods. To obtain cells for DNA extraction, strains were grown on rabbit blood-HIA at $35^{\circ} \mathrm{C}$ for 3 to 4 days. The DNA extraction and purification procedures and the hydroxyapatite hybridization method have been described previously (6). Divergence in related sequences was estimated to be approximately $1 \%$ for each degree of decreased thermal stability in a heterologous reașsociated DNA duplex compared with that in the homologous reassociated DNA duplex (6). Divergence was calculated to the nearest $0.5 \%$. DNA was labeled enzymatically in vitro with $\left[\alpha-{ }^{32} \mathrm{P}\right] \mathrm{dCTP}$ by use of a nick translation reagent kit (GIBCO BRL, Gaithersburg, Md.). The guanine-plus-cytosine (GC) content of DNA was determined spectrophotometrically by the method of Marmur and Doty (22). The values obtained were normalized to a Proteus mirabilis control strain with a GC content of $40 \mathrm{~mol} \%$.

PCR amplification of rDNA. Template DNA for direct sequencing was produced by enzymatic amplification of $16 \mathrm{~S}$ rDNA by using the primers fD1 and rD1 described by Weisburg and coworkers (48). The restriction enzyme linker region present in the original oligonucleotides was omitted, resulting in a primary structure for fD1 of 5'-AGAGTTT GATCCTGGCTCAG-3' and a primary structure for $\mathrm{rD} 1$ of 5'-AAGGAGGTGATCCAGCC-3'. In addition, primer rD1 was labeled at the $5^{\prime}$ end with biotin during oligonucleotide synthesis with biotinylated phosphoramidites (Cambridge Research Biochemicals, Wilmington, Del.). Approximately $10 \mathrm{ng}$ of bacterial genomic DNA was amplified in a $100-\mu \mathrm{l}$ reaction containing $10 \mathrm{pmol}$ of each primer, $200 \mu \mathrm{mol}$ each of dATP, dCTP, dGTP, and dTTP (Pharmacia LKB Biotechnology Inc., Piscataway, N.J.), and 2.5 U of AmpliTaq DNA polymerase (U.S. Biochemical, Cleveland, Ohio) in $1 \times$ GeneAmp polymerase chain reaction (PCR) buffer (PerkinElmer Corp., Norwalk, Conn.). Amplification was carried out in a Perkin-Elmer DNA thermal cycler under the following conditions: an initial 3-min DNA denaturation at $94^{\circ} \mathrm{C}$ was followed by 25 cycles consisting of $1 \mathrm{~min}$ at $94^{\circ} \mathrm{C}, 1 \mathrm{~min}$ at $45^{\circ} \mathrm{C}$, and $1.5 \mathrm{~min}$ at $72^{\circ} \mathrm{C}$. During the last cycle, the incubation at $72^{\circ} \mathrm{C}$ was increased to $5 \mathrm{~min}$ to allow for complete extension of PCR products.

PCR products were purified by using Dynabead M-280 streptavidin-coated magnetic beads (Dynal Inc., Great Neck, N.Y.) and a modification of the method of Hultman and associates (16). The beads were washed three times in saline buffer (1 M NaCl, $20 \mathrm{mM}$ Tris-HCl [pH 7.5], $1 \mathrm{mM}$ EDTA) and were resuspended in this buffer at their original concentration of $10 \mathrm{mg} / \mathrm{ml}$. A pool of five amplification reactions was added to $200 \mu$ l of beads, and the mixture was incubated at ambient temperature, with mixing, for $15 \mathrm{~min}$. A neodymium-iron-boron permanent magnet was used to sequester the beads and bound DNA, the supernatant was discarded, and the beads were washed once with $250 \mu$ l of TE buffer (10 mM Tris-HCl [pH 8.0], $1 \mathrm{mM}$ EDTA). The bound DNA was denatured by adding $50 \mu \mathrm{l}$ of $0.1 \mathrm{M} \mathrm{NaOH}$. After $15 \mathrm{~min}$ of incubation, the supernatant containing the eluted DNA strand was removed, neutralized with $5 \mu \mathrm{l}$ of 1 $\mathrm{M} \mathrm{HCl}$, and buffered to pH 7.5 by adding $5 \mu \mathrm{l}$ of $1 \mathrm{M}$ Tris- $\mathrm{HCl}$; the total volume was adjusted to $75 \mu$ l with $\mathrm{H}_{2} \mathrm{O}$. The DNA strand left bound to the beads was washed once with $250 \mu$ l of $\mathrm{NaOH}$ and three times with TE and was suspended in $75 \mu$ l of water.

Sequencing method and data analyses. Seven microliters of bead suspension (possessing the DNA strand complementary to the 16S rRNA) or eluted DNA strand solution was used for each sequencing reaction. Reactions were accomplished with T7 DNA polymerase (Sequenase 2.0; U.S. Biochemical), incorporating $\left[\alpha^{-{ }^{35}} \mathrm{~S}\right] \mathrm{dATP}$ as the label. The set of 10 oligonucleotides used as sequencing primers for the eluted strand has been described previously (39). Reverse complementary oligonucleotides to the 10 oligonucleotides were used to sequence the bound strand. Sequencing reactions were resolved on $8 \%$ polyacrylamide gels containing 7 $M$ urea (Marathon Gel-Mix 8; GIBCO BRL). After electrophoresis, the gels were transferred directly to paper and 
dried under vacuum. Autoradiographs were allowed to expose for 2 to 7 days.

The 16S rRNA sequences of 16 species of the order Rickettsiales and Anacystis nidulans were aligned by using the multisequence alignment program PILEUP, which is part of the GCG software package (12). Previously published sequences $(1,26,28,39,40,48,49)$ were obtained from the GenBank data base. The sequence alignment was edited to remove regions of alignment uncertainty, leaving 1,263 positions for calculation of evolutionary distance. Phylogenetic relationships were inferred with version 3.4 of the PHYLIP software package (15). A similarity matrix was calculated by the method described by Jukes and Cantor (17). The dendrogram was constructed by using the neighbor-joining method of Saitou and Nei (34).

Nucleotide sequence accession numbers. The sequence for $R$. elizabethae F9251 has been deposited in the GenBank, EMBL, and DDBJ data bases under accession number L01260. The sequence for $R$. vinsonii was submitted to the same data bases under accession number L01259.

\section{RESULTS}

Case report. A 31-year-old man presented with a 2-month history of fatigue, malaise, anorexia, and shortness of breath accompanied by a weight loss of $9 \mathrm{~kg}$. He had sustained lacerations on the third and fourth fingers of his left hand 2 weeks before the onset of these symptoms. There was no history of intravenous drug use, exposure to pets or other animals, recent dental work, or significant medical conditions. In the patient's medical record, there was no mention of the circumstances leading to the lacerations. He was born in Puerto Rico.

On initial evaluation, the patient had an oral temperature of $39^{\circ} \mathrm{C}$, a blood pressure of $105 / 40 \mathrm{~mm} \mathrm{Hg}$, multiple infected teeth, a 4/6 diastolic murmur of aortic regurgitation, an S3 cardiac gallop, and a splinter hemorrhage in the left index finger. A two-dimensional echocardiogram revealed large vegetations on the aortic valve and severe aortic regurgitation. A serum test for HIV antibody yielded negative results.

The patient became afebrile after $48 \mathrm{~h}$ of therapy with intravenous nafcillin and gentamicin, and he remained without fever throughout his hospitalization. A stool examination showed larvae of Strongyloides stercoralis, and the patient was treated with thiabendazole for 2 days. He developed increasing congestive heart failure, and a decision was made to replace his aortic valve surgically.

On the 16th hospital day, seven infected teeth were removed. On the 17th hospital day, because of concern about a prolonged bleeding time of greater than $15 \mathrm{~min}$ and the patient's imminent surgery, the antibiotic regimen was changed to vancomycin and imipenem. On the next day, the patient underwent aortic valve replacement. During the operation, he was found to have a tricuspid aortic valve with vegetations on all three cuspids (Fig. 1). Gram staining of the aortic tissue vegetation appeared to show abundant minute coccobacillary organisms.

The patient recovered from surgery and was discharged on the 24th postoperative day, after 6 weeks of intravenous antibiotic therapy. He was treated as an outpatient with oral trimethoprim-sulfamethoxazole for 5 additional weeks. There was no evidence of relapse or recurrence of endocarditis for the subsequent 2.5 years, after which he was lost to follow-up.

Primary isolation. Cultures of blood samples drawn before the patient received antimicrobial therapy showed no visible growth after 3 weeks of incubation. Subculture of a sample from the aerobic bottle done approximately 1 week after inoculation grew small, dry colonies that were adherent to the agar and that were noticed after 14 days of incubation on blood and chocolate agars at $35^{\circ} \mathrm{C}$ in 5 to $10 \% \mathrm{CO}_{2}$. Repeat subculture from both the aerobic and anaerobic bottles yielded a faint growth of dry, rough colonies after 10 days, confirming the original isolation of strain F9251, which was subsequently recognized as a Rochalimaea-like organism.

Cultures of blood obtained 2 days after the start of therapy with nafcillin and gentamicin were negative. Cultures of the tissue from the aortic valve grew catalase-positive anaerobic diphtheroids in broth medium after 2 weeks of incubation. These organisms were thought to be contaminants and were not further identified.

Strain F9251 grew best on chocolate or sheep blood-TSA at $35^{\circ} \mathrm{C}$ in 5 to $10 \% \mathrm{CO}_{2}$. It did not grow aerobically at $42^{\circ} \mathrm{C}$, anaerobically, in stationary broth media, on Campy BAP plates, or on Thayer-Martin plates containing antibiotics. After multiple passages, the growth rate increased and colonies that were less adherent to the agar than the initial isolate could be seen after 48 to $72 \mathrm{~h}$ of incubation.

Phenotypic characteristics. Gram staining revealed thin, short, straight and slightly curved gram-negative bacilli (Fig. 2). Catalase, oxidase, and spot indole tests were negative. On initial isolation, the organism could not be identified as a known species. It was subsequently sent to the Massachusetts State Laboratory Institute and CDC. Neither of those laboratories could identify the organism.

However, after a Rochalimaea species was isolated in a patient with bacillary angiomatosis and bacteremia and the phenotypic characteristics of $R$. henselae were described $(28,37,52)$, strain F9251 was recognized as being Rochalimaea-like and was reexamined. In the RapID ANA II system, Rochalimaea-like strain F9251 cleaved leucylglycine, glycine, proline, phenylalanine, arginine, and serine, yielding the code number 000671, which is identical to that obtained for $R$. henselae (28).

The phenotypic characteristics of strain F9251 were compared with those of known Rochalimaea species (Table 1). There were few positive characteristics other than the hydrolysis of the same six substrates. The oxidase reaction, when tested by the Kovacs procedure, was weakly positive at $9 \mathrm{~s}$ for strains of $R$. quintana and $R$. vinsonii but was negative for three strains of $R$. henselae and for strain F9251. Strain F9251, the type strains of $R$. quintana and $R$. vinsonii, and one of three $R$. henselae strains grew within $72 \mathrm{~h}$ on HIA around an X (hemin) strip. All the Rochalimaea strains grew on HIA supplemented with rabbit blood. F9251 produced a zone of incomplete clearing (not greening) on rabbit bloodHIA after incubation for 3 to 4 days.

Antibiotic susceptibility. Strain F9251 was susceptible to all antibiotics tested (erythromycin, ciprofloxacin, cefoxitin, gentamicin, vancomycin, and oxacillin).

Cell wall fatty acids. The CFA compositions of each Rochalimaea species and Rochalimaea-like strain F9251 were characterized by using large amounts of cis-11-octadecanoate $\left(C_{18: 1 \omega 7 c}\right)$, hexadecanoate $\left(C_{16: 0}\right)$, and octadecanoate $\left(C_{18: 0}\right)$, which accounted for 64 to $97 \%$ of total acids (Table 2). In addition, all contained $C_{17: 0}(1$ to $21 \%$ ) and trace to small amounts of $C_{16: 1 \omega 7 c}, C_{17: 1 \omega 6 c}, C_{18: 2}$, and $C_{18: 1 \omega 9 c}$. No hydroxy or cyclopropane acids were present.

GC content and DNA relatedness. Spectrophotometric assessments showed that the GC content of DNA from strain F9251 was $41.0 \mathrm{~mol} \%$; those of the type strains of Rochalimaea species were $40.3 \mathrm{~mol} \%$ for $R$. quintana, $41.1 \mathrm{~mol} \%$ 


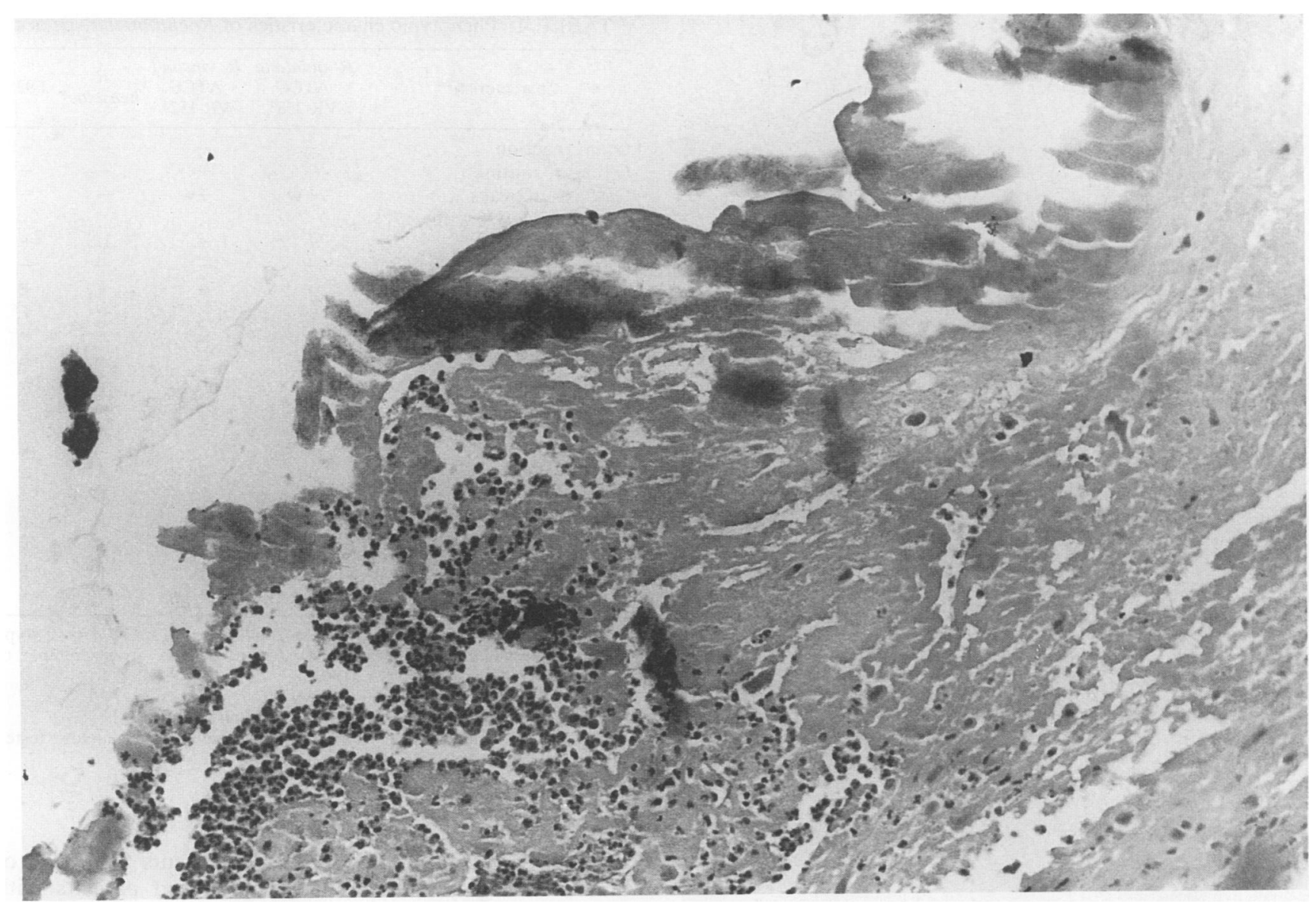

FIG. 1. Hematoxylin-eosin-stained section of aortic valve showing fibrin vegetation with acute inflammation and necrosis of underlying valve substance. Magnification, $\times 125$.

for $R$. vinsonii, and $41.0 \mathrm{~mol} \%$ for $R$. henselae. Labeled DNA from strain F9251 was 59 to $67 \%$ related to type strains of the three described Rochalimaea species at $55^{\circ} \mathrm{C}$, an optimal DNA reassociation criterion (Table 3 ). The divergence in related sequences was 12 to $13 \%$, and the relatedness under a stringent criterion for DNA reassociation was approximately $15 \%$. In reciprocal reactions with labeled DNA from $R$. henselae, the relatedness was $49 \%$, with $9.5 \%$ divergence and $16 \%$ relatedness at $75^{\circ} \mathrm{C}$.

16S rRNA sequence analysis. The partial 16S rRNA gene sequence from strain F9251 is shown in Fig. 3 and is aligned with sequences from other species of Rochalimaea and $B$. bacilliformis. A total of 1,466 nucleotide positions, corresponding to Escherichia coli sequence positions 23 to 1,496 (8), were determined. This represents approximately $95 \%$ of the gene. An identical region of the 16S rRNA gene from $R$. vinsonii was also sequenced. These data show good agreement with a $16 \mathrm{~S}$ gene sequence from the same strain of $R$. vinsonii reported by Regnery et al. (28). In an overlapping region of 1,415 nucleotides between these two sequences, only a single discrepancy was noted, the occurrence of a guanosine residue at position 875 in Fig. 3 which does not appear in the previously published sequence. The 16S rRNA sequence of $B$. bacilliformis type strain ATCC 35695 was first determined, using reverse transcriptase, by O'Connor and others (26) and was subsequently determined by Birtles and colleagues (4) and Relman and coworkers (31). Because of discrepancies between these reported sequences, a 1,471nucleotide $16 \mathrm{~S}$ rDNA sequence from $B$. bacilliformis ATCC 35685 was again determined. The corrected sequence shown in Fig. 3 has been submitted to GenBank, where it appears under the original accession number (M65249).

A sequence similarity matrix based on $16 \mathrm{~S}$ sequence data from members of the family Rickettsiaceae is shown in Table 4. The sequence from strain F9251 was most similar (99.4\%) to the $R$. vinsonii sequence, $99.2 \%$ similar to the $R$. henselae sequence, and $98.9 \%$ similar to the $R$. quintana sequence. Within the genus Rochalimaea an average similarity value of 99.3\% was calculated. The sequence from $B$. bacilliformis exhibited a high degree of similarity to the sequences from the three Rochalimaea species and strain F9251, with an average value of $98.5 \%$ (this value is higher than that reported previously [26] because of corrections to the Bartonella sequence and masking of the sequences to remove ambiguous regions from the alignment). By grouping these five sequences, an average similarity of $99.0 \%$ is obtained. The phylogenetic ordering of these organisms is demonstrated in the dendrogram shown in Fig. 4. Rochalimaea species and $B$. bacilliformis form a tight cluster with a common line of descent separate from the genera Rickettsia and Ehrlichia. 


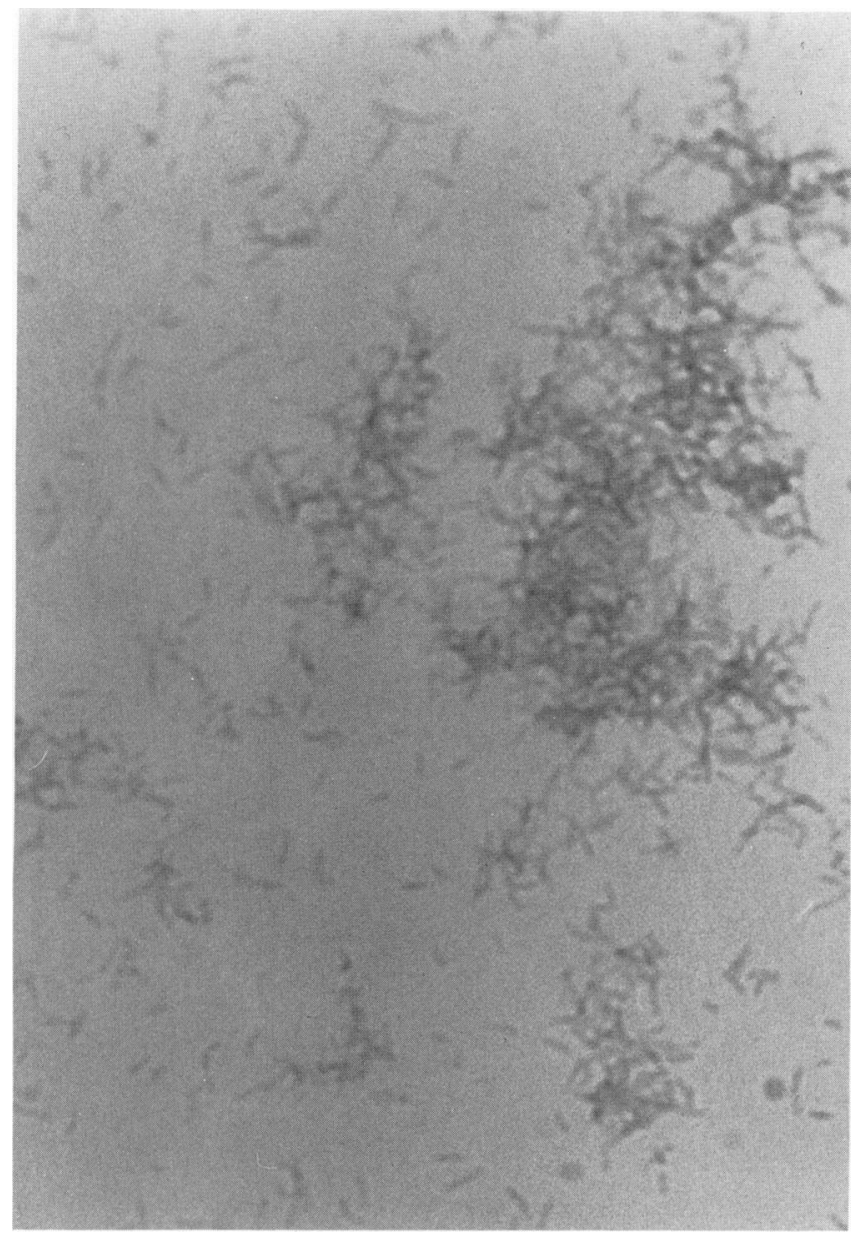

FIG. 2. Gram-stained smear of strain F9251 taken from a colony grown on a chocolate agar incubated for $96 \mathrm{~h}$ at $35^{\circ} \mathrm{C}$ in $5 \% \mathrm{CO}_{2}$. Magnification, $\times 1,250$.

\section{DISCUSSION}

Our patient initially presented with culture-negative endocarditis, an entity that is becoming increasingly rare as laboratories develop better techniques for culturing fastidious organisms $(41,43)$. Because our patient's history, clinical evaluation, and echocardiographic findings provided compelling evidence of bacterial endocarditis, we used assessment methods designed to enhance the detection of fastidious organisms. Strain F9251 was isolated only when an aliquot of broth containing the patient's blood was subcultured onto chocolate agar plates and the plates were kept for 14 days in an atmosphere of 5 to $10 \% \mathrm{CO}_{2}$. Standard clinical laboratory practice would have dictated holding the subculture plates for only 48 to $72 \mathrm{~h}$, an incubation period which is usually adequate for recovery of organisms known to cause endocarditis, such as of the Haemophilus-Actinobacillus-Cardiobacterium-Eikenella-Kingella group (46). In contrast, Rochalimaea species require 10 to 21 days to grow after subculture from broth medium or after culture of blood samples by the lysis-centrifugation method (37). Our experience in isolating F9251 and appreciation of the techniques required to isolate the other Rochalimaea species from blood or tissue specimens $(28,37,52)$ indicate that changes are necessary in the methods of blood culture processing in
TABLE 1. Phenotypic characteristics of Rochalimaea species

\begin{tabular}{|c|c|c|c|c|}
\hline Characteristic $^{a}$ & $\begin{array}{l}\text { R. quintana } \\
\text { ATCC } \\
\text { VR-358 }^{\mathrm{T}}\end{array}$ & $\begin{array}{l}\text { R. vinsonii } \\
\text { ATCC } \\
\text { VR-152 }\end{array}$ & $\begin{array}{c}R . \\
\text { henselae }\end{array}$ & F9251 \\
\hline Gram reaction & - & - & - & - \\
\hline Oxidase, routine & - & - & - & - \\
\hline Oxidase, Kovacs & $+w$ & $+w$ & - & - \\
\hline \multicolumn{5}{|l|}{ Growth on HIA with: } \\
\hline $\mathrm{X}$ factor & + & + & $1 / 3$ & + \\
\hline$V$ factor & - & - & - & - \\
\hline Rabbit blood & + & + & + & + \\
\hline Hemolysis & - & - & - & $t^{c}$ \\
\hline Motility & - & - & - & - \\
\hline Indole production, spot test & - & - & - & - \\
\hline Ornithine decarboxylase & - & - & - & - \\
\hline Urea, Christensen & - & - & - & - \\
\hline Acid from carbohydrates ${ }^{d}$ & - & - & - & - \\
\hline \multicolumn{5}{|l|}{ Hydrolysis of: } \\
\hline Leucylglycine & + & + & + & + \\
\hline Glycine & + & + & + & + \\
\hline Proline & + & + & + & + \\
\hline Phenylalanine & + & + & + & + \\
\hline Arginine & + & + & + & + \\
\hline Serine & + & + & + & + \\
\hline
\end{tabular}

${ }^{a}+$, positive reaction within $48 \mathrm{~h} ;-$, negative reaction after 7 days; $T$, type strain; $w$, weak reaction; fraction, number of positive strains/number of strains tested.

${ }^{b}$ Strains ATCC $49882^{\mathrm{T}}, 87-66$, and $88-712$.

c Zone of incomplete clearing at 3 to 4 days on rabbit blood.

${ }^{d}$ D-Glucose, lactose, maltose, D-mannitol, D-xylose, and sucrose tested with a rapid sugar test $(10)$

patients with suspected endocarditis, patients with fever of unknown origin, and immunocompromised patients with fever (28), in order to allow recognition of the full spectrum of diseases associated with Rochalimaea and related species.

Organisms that are difficult to identify and that appear to be Rochalimaea-like species should be tested for preformed enzymes, and their CFA composition should be determined. Since the reactions of all the Rochalimaea strains we tested in the RapID ANA II system (profile number 000671) were the same as those for the type strain of $R$. henselae (28), the system may be useful for identification to the genus level, although it does not differentiate between the species of Rochalimaea. The only phenotypic characteristic that distinguished strain F9251 from the strains of the other species was a delayed hemolytic reaction on rabbit blood agar. At present, only DNA hybridization, 16S rRNA sequencing, and PCR-restriction endonuclease fragment length polymorphism analysis of the citrate synthase gene $(18,28)$ can be used to identify Rochalimaea isolates to the species level. Presumably, a species-specific antiserum, such as that produced from $R$. henselae by Welch and coworkers (52), could be prepared against strain F9251 for use in identifying other strains. It may be possible to develop genus-specific Rochalimaea antiserum to aid in identification.

The presence and relative amounts of the fatty acids in Rochalimaea species are unique for this genus and currently represent the most practical and rapid way to differentiate these organisms from other bacterial genera. Initially, CFA data provided a strong indication that strain F9251 was in the genus Rochalimaea and was possibly a new species. These data showed that the CFA content of F9251 was typical of, but not identical to, that of other Rochalimaea species. $R$. henselae and $R$. quintana have virtually identical CFA 
TABLE 2. CFA composition of Rochalimaea species

\begin{tabular}{|c|c|c|c|c|c|c|c|c|c|c|}
\hline \multirow{2}{*}{$\begin{array}{c}\text { Organism } \\
\text { (no. of strains tested) }\end{array}$} & \multicolumn{10}{|c|}{$\%$ Fatty acids ${ }^{a}$} \\
\hline & $\mathrm{C}_{15: 0}$ & $C_{16: 1 \omega 7 c}$ & $C_{16: 0}$ & $\mathrm{C}_{17: 1 \omega 8 \mathrm{c}}$ & $C_{17: 1 \omega 6 c}$ & $C_{17: 0}$ & $C_{18: 2}$ & $\mathrm{C}_{18: 1 \omega 9 \mathrm{c}}$ & $C_{18: 1 \omega 7 \mathrm{c}}$ & $C_{18: 0}$ \\
\hline R. henselae (7) & - & $\operatorname{Tr}$ & 17 & - & $\operatorname{Tr}$ & 3 & 1 & 1 & 57 & 20 \\
\hline R. quintana (8) & - & $\operatorname{Tr}$ & 18 & - & $\operatorname{Tr}$ & 1 & $\operatorname{Tr}$ & $\operatorname{Tr}$ & 59 & 21 \\
\hline R. vinsonii (1) & 2 & 2 & 20 & - & 3 & 9 & $\operatorname{Tr}$ & $\mathrm{Tr}$ & 54 & 9 \\
\hline $\begin{array}{l}\text { Rochalimaea-like strain } \\
\text { F9251 (1) }\end{array}$ & 2 & 1 & 13 & 1 & 8 & 21 & 1 & 1 & 43 & 8 \\
\hline
\end{tabular}

a Numbers before the colons are the numbers of carbon atoms; numbers after the colons are the numbers of double bonds; $\omega$, double-bond position from the hydrocarbon end of the carbon chain; $c$, cis isomer; values are the mean percentages of total fatty acids; Tr, 0.4 to $0.9 \%$; - , not detected.

features and cannot be distinguished from each other by fatty acid analysis. $R$. vinsonii and strain F9251 had similar CFA compositions, which differed from those of $R$. quintana and $R$. henselae by the presence of $\mathrm{C}_{15: 0}, \mathrm{C}_{17: 1 \omega 6 \mathrm{c}}$, and larger amounts of $\mathrm{C}_{17: 0}$. However, strain $\mathrm{F} 9251$ contained more $\mathrm{C}_{17: 0}$ and less $\mathrm{C}_{16: 0}$ and $\mathrm{C}_{18: 1 \omega 7 \mathrm{c}}$ than did $R$. vinsonii. Although the differences in CFA composition remained consistent upon repeated regrowth and retesting of each species, they must be considered tentative until additional strains are tested. The data in Table 2 are in general agreement with those reported by Welch and associates (52), except that the $C_{13: 1}$ acid observed by those investigators was not present in any Rochalimaea strain that we tested.

There were other differences between our results and those reported previously. Our results indicate that the GC contents of strain F9251 and named Rochalimaea species were between 40.3 and $41.1 \mathrm{~mol} \%$. These values were greater than the level of approximately $39 \mathrm{~mol} \%$ previously observed for $R$. quintana and $R$. vinsonii $(42,50)$. All GC determinations made by us and others were done spectrophotometrically by means of thermal denaturation analysis. We used the equation of Marmur and Doty (22) whereas the earlier evaluations used the equation of De Ley (11) to determine the mol\% GC from thermal denaturation. The resulting difference in values was probably due to either impurities in the DNA used or the calibration temperatures of the spectrophotometer.

DNA-DNA hybridization remains the method of choice for defining species $(24,47)$. The high level of DNA relatedness of Rochalimaea-like strain F9251 to the three described Rochalimaea species (49 to 67\%; Table 3) leaves little doubt that it represents a new species in the genus Rochalimaea. The 16S rRNA sequence of F9251 is most homologous to the 16S rRNA sequences of the three existing Rochalimaea species $(98.9 \%$ or greater), supporting placement of this strain in the genus Rochalimaea. The magnitudes of dissimilarity between the F9251 sequence and the other three Rochalimaea sequences are similar to those obtained by comparing the sequences from the three Rochalimaea species previously defined by DNA-DNA hybridization (52). These findings, as well as the similarities observed in the cultural, biochemical, and CFA characteristics, support the classification of F9251 as a new species in the genus Rochalimaea. We propose the name Rochalimaea elizabethae sp. nov. for this organism. The description of the new species is given below.

The topology of the tree in Fig. 4 reveals that the genus Rochalimaea is a monophyletic group which shares a common line of descent with $B$. bacilliformis, a phylogenetic relationship that has been noted previously $(4,26,31)$. The 16S rRNA sequence reported by O'Connor et al. (26) was $91.7 \%$ homologous to that of $R$. quintana. This level of homology was well below that expected from the 32 to $47 \%$ DNA relatedness between $B$. bacilliformis and Rochalimaea species shown previously (52) and in the present study. We therefore resequenced $B$. bacilliformis 16S rRNA (Fig. 3), obtaining $98.4 \%$ homology with $R$. quintana (Table 4 ). In conjunction with the hybridization results, the genetic data support the reclassification of the genus Rochalimaea into the family Bartonellaceae and suggest the reordering of these organisms into a single genus.

$B$. bacilliformis and Rochalimaea species are related both genetically and by similarities in their associated clinical presentations and transmission by vectors. As Welch and colleagues (52) have observed, the histologic appearance of bacillary angiomatosis (27); the chronic form of bartonellosis, verruga peruana; cat scratch disease; and Kaposi's sarcoma show some similarities. Transmission by a vector

TABLE 3. DNA relatedness of Rochalimaea species

\begin{tabular}{|c|c|c|c|c|c|c|}
\hline \multirow{3}{*}{ Source of unlabeled DNA } & \multicolumn{6}{|c|}{ \% Relatedness to labeled DNA from: } \\
\hline & \multicolumn{3}{|c|}{ Rochalimaea-like strain F9251 } & \multicolumn{3}{|c|}{$R$. henselae ATCC $49882^{\mathrm{T}}$} \\
\hline & $55^{\circ} \mathrm{C}$ & $\mathrm{D}^{a}$ & $70^{\circ} \mathrm{C}$ & $55^{\circ} \mathrm{C}$ & D & $70^{\circ} \mathrm{C}$ \\
\hline Rochalimaea-like strain F9251 & 100 & 0.0 & 100 & 49 & 9.5 & 16 \\
\hline R. henselae ATCC $49882^{\mathrm{T}}$ & 67 & 12.5 & 16 & 100 & 0.0 & 100 \\
\hline R. henselae $89-674$ & & & & 100 & 1.0 & 100 \\
\hline R. henselae $90-615$ & & & & 99 & 0.5 & 98 \\
\hline R. henselae 87-66 & & & & 100 & 0.0 & 100 \\
\hline R. henselae 89-712 & & & & 92 & 1.0 & 99 \\
\hline R. quintana ATCC VR-358 ${ }^{\mathrm{T}}$ & 59 & 13.0 & 15 & & & \\
\hline R. vinsonii ATCC VR-152 & 66 & 12.0 & 16 & & & \\
\hline B. bacilliformis ATCC $35685^{\mathrm{T}}$ & 32 & 17.0 & & 47 & 16.5 & \\
\hline
\end{tabular}

${ }^{a} \mathrm{D}$, divergence within related sequences, calculated to the nearest $0.5 \%$. 
$1 \underline{\mathbf{v}}$

TCCTG GCTCAGAACG AACGCTGGCG 100 V GCTCAGAACG AACGCTGGCG GCAGGCTTAA CACATGCAAG TCGAGCGCAC TCTTTTAGAG TGAGCGGCAA ACGGGTGAGT AACGCGTGGG
CTCAGAACG AACGCTGGCG GCAGGCTTAA CACATGCAAG TCGAGCGCAC TCTTTTAGA TGAGCGGAA ACGGGTGAGT AACGCGTGGG TCCTG GCTCAGAACG AACGCTGGCG GCAGGCTTAA CACATGCAAG TCGAGCGGCT CCTTTTGGAG CGAGCGGCAA ACGGGTGAGT AACGCGTGGG TTTGATCCTG GCTCAGAACG AACGCTGGCG GCAGGCTTAA CACATGCAAG TCGAGCGCAC TCTTTTGCAG TGAGCGGCAA ACGAGTGAGT AACGCGTGGG

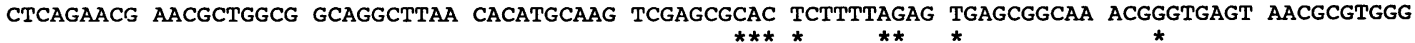

$\mathrm{RQ}$

$$
\star * * *
$$

$200 \nabla$

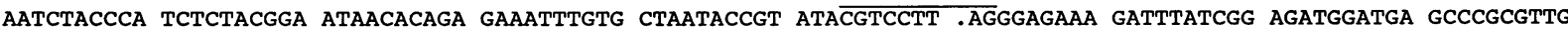
AATCTACCCA TCTCTACGGA ATAACACAGA GAAATTTGTG CTAATACCGT ATACGTCCTT .AGGGAGAAA GATTTATCGG AGATGGATGA GCCCGCGTTG AATCTACCCC TCTCTACGGA ATAACACAGA GAAATTTGTG CTAATACCGT ATACBTCCCT .TTGGAGAAA GATTTATCGG AGATGGATGA GCCCGCGTTG AATCTACCCA TCTCTACGGA ATAACACAGA CAAATTTGTG CTAATACAGT ATACGTCCTT . CGGGAGAAA GATTTATCGG AGATGGATGA GCCCGCGTTG

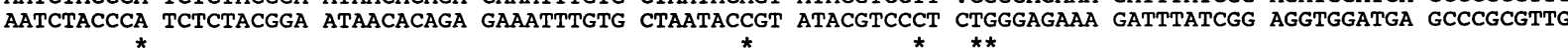
*

$300 \mathrm{v}$

GATTAGCTAG TTGgTGAgGT AACGGCTCAC CAAGGCGACG ATCCATAGCT GGTCTGAGAG GATGATCAGC CACACTGGGA CTGAGACACG GCCCAGACTC GATTAGCTAG TTGGTGAGGT AACGGCTCAC CAAGGCGACG ATCCATAGCT GGTCTGAGAG GATGATCAGC CACACTGGGA CTGAGACACG GCCCAGACTC GATTAGCTAG ITGGTGAGGT AACGGCTCAC CAAGGCGACG ATCCATAGCT GGTCTGAGAG GATGATCAGC CACACTGGGA CTGAGACACG GCCCAGACTC GATTAGCTAG ITGGTGAGGT AACGGCCCAC CAAGGCGACG ATCCATAGCT GGTCTGAGAG GATGATCAGC CACACTGGGA CTGAGACACG GCCCAGACTC GATTAGCTAG TTGGTGAGGT AAGGGCTCAC CAAGGCGACG ATCCATAGCT GGTCTGAGAG GATGATCAGC CACACTGGGA CTGAGACACG GCCCAGACTC *

$400 \mathrm{~V}$ CTACGGGAGG IAGCAGTGGG GAATATTGGA CAATGGGGGC AACCCTGATC CAGCCATGCC GCGTGAGTGA TGAAGGCCCT AGGGTTGTAA AGCTCTTTCA CTACGGGAGG CAGCAGTGGG GAATATTGGA CAATGGGGGC AACCCTGATC CAGCCATGCC GCGTGAGTGA TGAAGGCCCT AGGGTTGTAA AGCTCTTTCA CTACGGGAGG CAGCAGTGGG GAATATTGGA CAATGGGGGC AACCCTGATC CAGCCATGCC GCGTGAGTGA TGAAGGCCCT AGGGTTGTAA AGCTCTTTCA CTACGGGAGG DAGCAGTGGG GAATATTGGA CAATGGGGGC AACCCTGATC CAGCCATGCC GCGTGAGTGA TGAAGGCCTT AGGGTTGTAA AGCTCTTTCA CTACGGGAGG CAGC̣ATTGG GAATATTGGA CAATGGGGGC AACCCTGATC CAGCCATGCC GCGTGAGTGA TGAAGGCCCT AGGGTTGTAA AGCTCTTTCA

500 V

CCGGTGAAGA TAATGACGgT AACCGGAGAA GAAGCCCCGG CTAACTTCGT GCCAGCAGCC GCGGTAATAC GAAGGGGGCT AGCGTTGTTC GGATTTACTG CCGGTGAAGA 'TAATGACGGT AACCGGAGAA GAAGCCCCGG CTAACTTCGT GCCAGCAGCC GCGGTAATAC GAAGGGGGCT AGCGTTGTTC GGATTTACTG CCGGTGAAGA TAATGACGGT AACCGGAGAA GAAGCCCCGG CTAACTTCGT GCCAGCAGCC GCGGTAATAC GAAGGGGGCT AGCGTTGTTC GGATTTACTG CCGGTGAAGA TAATGACGGT AGCCGGAGAA GAAGCCCCGG CTAACTTCGT GCCAGCAGCC GCGGTAATAC GAAGGGGGCT AGCGTTGTTC GGATTTACTG CCGGTGAAGA TAATGACGTT AACCGGAGAA GAAGCCCCGG CTAACTTCGT GCCAGCAGCC GCGGTAATAC GAAGGGGGCT AGCGTTGTTC GGATTTACTG

$600 \vee$

GGCGTAAAGC GCACGTAGGC GGATATTTAA GTCAGAGGTG AAATCCCAGG GCTCAACCCT GGAACTGCCT TTGATACTGG GTATCTTGAG TATGGAAGAG GGCGTAAAGC GCATGTAGGC GGATATTTAA GTCAGAGGTG AAATCCCAGG GCTCAACCCT GGAACTGCCT TTGATACTGG GTATCTTGAG TGTGGAAGAG GGCGTAAAGC GCACGTAGGC GGATATTTAA GTCAGAGGTG AAATCCCAGG GCTCAACCCT GGAACTGCCT TTGATACTGG ATATCTTGAG TGTGGAAGAG GGCGTAAAGC GCATGTAGGC GGATATTTAA GTCAGAGGTG AAATCCCAGG GCTCAACCTT GGAACTGCCT TTGATACTGG ATGTCTCGAG TATGGAAGAG GGCGTAAAGC GCATGTAGGC GGATATTTAA GTCAGAGGTG AAATCCCAGG GCTCAACCCT GGAACTGCCT TTGATACTGG ATGTCTCGAG TGTGGAAGAG * * $* *$

$700 \mathrm{~V}$

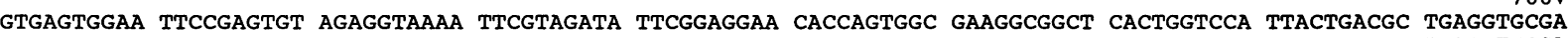
GTGAGTGGAA TTCCGAGTGT AGAGGTAAAA TTCGTAGATA TTCGGAGGAA CACCAGTGGC GAAGGCGGCT CACTGGTCCA TTACTGACGC TGAGGTGCGA GTGAGTGGAA TTCCGAGTGT AGAGGTAAAA TTCGTAGATA TTCGGAGGAA CACCAGTGGC GAAGGCGGCT CACTGGTCCA TTACTGACGC TGAGGTGCGA GTGAGTGGA TTCCGAGTGT AGAGGTAAAA TTCGTAGATA TTCGGAGGA CACCAGTGGC GAaGGCGGCT CACTGGTCCA TTACTGACGC TGAGGTGCGA GTGAGTGGAA TTCCGAGTGT AGAGGTAAAA TTCGTAGATA TTCGGAGGAA CACCAGTGGC GAAGGCGGCT CACTGGTCCA TTACTGACGC TGAGGTGCGA

$800 \mathrm{~V}$

AAGCGTGGG AGCAAACAGG ATTAGATACC CTGGTAGTCC ACGCCGTAAA CGATGAATGT TAGCCGTCGg GCGGTTTACT GCTCGGTGGC GCACGTAACG AAGCGTGGG AGCAAACAGG ATTAGATACC CTGGTAGTCC ACGCCGTAAA CGATGAATGT TAGCCGTCGG GCGGTTTACT GCTCGGTGGC GCACGTAACG AAGCGTGGGG AGCAAACAGG ATTAGATACC CTGGTAGTCC ACGCCGTAAA CGATGAATGT TAGCCGTCGG GCGGTTTACT GCTCGGTGGC GCACGTAACG AAGCGTGGGG AGCAAACAGG ATTAGATACC CTGGTAGTCC ACGCCGTAAA CGATGAATGT TAGCCGTCGG GCAGTTTACT GCTCGGTGGC GCACGTAACG AAGCGTGGG AGCAAACAGG ATTAGATACC CTGGTAGTCC ACGCCGTAAA CGATGAATGT TAGCCGTCGG GTGGTTTACT ACTCGGTGGC GCACGTAACG

$900 \mathrm{~V}$

CATTAAACAT TCCGCCTGGG GAGTACGGTC GCAAGATTAA AACTCAAAGG AATTGACGGG GGCCCGCACA AGCGGTGGAG CATGTGGTTT AATTCGAAGC CGTTAAACAT ITCCGCCTGGG GAGTACGGTC GCAAGATTAA AACTCAAAGG AATTGACGGG GGCCCGCACA AGCG. TGGAG CATGTGGTTT AATTCGAAGC CATTAAACAT TCCGCCTGGG GAGTACGGTC GCAAGATTAA AACTCAAAGG AATTGACGGG GGCCCGCACA AGCGGTGGAG CATGTGGTTT AATTCGAAGC CATTAAACAT 'TCCGCCTGGG GAGTACGGTC GCAAGATTAA AACTCAAAGG AATTGACGGG GGCCCGCACA AGCGGTGGAG CATGTGGTTT AATTCGAAGC CGTTAAACAT 'TCCGCCTGGG GAGTACGGTC GCAAGATTAA AACTCAAAGG AATTGACGgG GGCCCGCACA AGCG. TGGAG CATGTGGTTT AATTCGAAGC

1000 V

AACGCGCAGA ACCTTACCAG CCCTTGACAT CCCGATCGCG GAAGGTGGAG ACACCCTCCT TCAGTTAGGC TGGATCGGAG ACAGGTGCTG CATGGCTGTC AACGCGCAGA ACCTTACCAG CCCTTGACAT CCCGATCGCG GAAGGTGGAG ACACCCTCCT TCAGTTAGGC TGGATCGGAG ACAGGTGCTG CATGGCTGTC AACGCGCAGA ACCTTACCAG CCCTTGACAT CCCGATCGCG GAGAGTGGAG ACACTCTCCT TCAGTTAGGC TGGATCGGAG ACAGGTGCTG CATGGCTGTC AACGCGCAGA $\triangle$ CCTTACCAG CCCTTGACAT CCCGATCGCG GAGAGTGGAG ACACTTTCCT TCAGTTAGGC TGGATCGGAG ACAGGTGCTG CATGGCTGTC AACGCGCAGA ACCTTACCAG CCCTTGACAT CCCGATCGCG GAAGTGGAG ACACCCTCCT TCAGTTAGGC TGGATCGGTG ACAGGTGCTG CATGGCTGTC GTCAGCTCGT GTCGTGAGAT GTTGGGTTAA GTCCCGCAAC GAGCGCAACC CTCGCCCTTA GTTGCCAGCA TTCAGTTGGG CACTCTAAGG GGACTGCCGG GTCAGCTCGT GTCGTGAGAT GTTGGGTTAA GTCCCGCAAC GAGCGCAACC CTCGCCCTTA GTTGCCAGCA TTTGGTTGGG CACTCTAGGG GGACTGCCGG GTCAGCTCGT GTCGTGAGAT GTTGGGTTAA GTCCCGCAAC GAGCGCAACC CTCGCCCTTA GTTGCCAGCA TTAAGTTGGG CACTCTAAGG GGACTGCCGG GTCAGCTCGT GTCGTGAGAT GTTGGGTTAA GTCCCGCAAC GAGCGCAACC CTCGCCCTTA GTTGCCAGCA TTCAGTTGGG CACTCTAAGG GGACTGCCGG GTCAGCTCGT GTCGTGAGAT GTTGGGTTAA GTCCCGCAAC GAGCGCAACC CTCGCCCTTA GTTGCCATCA TTAAGTTGGG CACTCTAGGG GGACTGCCGG

$1200 \mathrm{~V}$ TGATAAGCCG 2 GAGGAAGGT GGGGATGACG TCAAGTCCTC ATGGCCCTTA CGGGCTGGGC TACACACGTG CTACAATGGT GGTGACAGTG GGCAGCGAGA

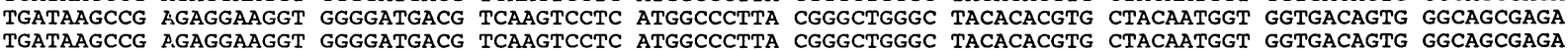
TGATAAGCCG P.GAGGAAGGT GGGGATGACG TCAAGTCCTC ATGGCCCTTA CGGGCTGGGC TACACACGTG CTACAATGGT GGTGACAGTG GGCAGCGAGA TGATAAGCCG AGAGGAAGGT GGGGATGACG TCAAGTCCTC ATGGCCCTTA CGGGCTGGGC TACACACGTG CTACAATGGT GGTGACAGTG GGCAGCGAGA

FIG. 3. Alignment of partial $16 \mathrm{~S}$ rRNA gene sequences from $R$. vinsonii (RV), $R$. henselae (RH), R. elizabethae (RE), B. bacilliformis (BB), and R. quintana (RQ). The sequence of the noncoding (RNA-like) strand is shown. Alignment gaps at positions 161 and 875 are indicated by dots. The asterisks indicate the lack of consensus at positions where the nucleotide sequence was determined for all genes in the alignment. The positions of alignment uncertainty, observed in an alignment of 16 sequences from members of the order Rickettsiales (data not shown) that were omitted from the phylogenetic analysis, are indicated by a line above these positions. 
CCGATC GAGCTAATCT CCAAAAGCCA TCTCAGTTCG GATTGCACTC TGC GCCA TCTCAGTTCG GATTGCACTC TGCAACTCGA GTGCATGAAG TCGGAATCGC TAGTAATCGT GGATCAGCAT CCGCGAGGTC GAGCTAATCT CCAAAAGCCA TCTCAGTTCG GATTGCACTC TGCAACTCGA GTGCATGAAG TTGGAATCGC TAGTAATCGT GGATCAGCAT CCGCAAGGTC GAGCTAATCT CCAAAAGCCA TCTCAGTTCG GATTGCACTC TGCAACTCGA GTGCATGAAG TCGGAATCGC TAGTAATCGT GGATCAGCAT CCGCGAGGTC GAGCTAATCT CCAAAAGCCA TCTCAGTTCG GATTGCACTC TGCAACTCGA GTGCATGAAG TTGGAATCGC TAGTAATCGT GGATCAGCAT
$\star$

GCCACGGTGA ATACGTTCCC GGGCCTTGTA CACACCGCCC GTCACACCAT GGGAGTTGGT TTTACCCGAA GGTGCTGTGC TAACCGCAAG GAGGCAGGCA GCCACGGTGA ATACGTTCCC GGGCCTTGTA CACACCGCCC GTCACACCAT GGGAGTTGGT TTTACCCGA GGTGCTGTGC TAACCGCAAG GGGGCAGGCA GCCACGG GA GCCACGGTCA ATACGTTCCC GGGCCITGTA CACACCGCCC GTCACACCAT GGGAGTTGGT TTTACCCGAA GGTGCTGTGC TAACCGCAAG GAAGCAGGCA GCCACGGTGA ATACGTTCCC GGGCCTTGTA CACACCGCCC GTCACACCAT GGGAGTTGGT TTTACCCGAA GGTGCTGTGC TAACCGCAAG GAGGCAGGCA

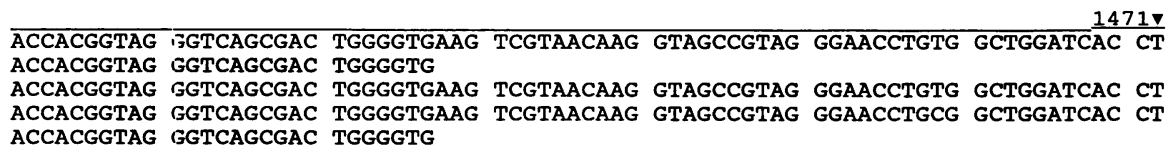

FIG. 3-Continued

has been suggested for $R$. vinsonii, which was isolated from the spleens of voles and then experimentally transmitted by the ear mite (Trombicula microti) to a hamster by Baker (2). $B$. bacilliformis and $R$. quintana are transmitted by vectors to humans $(25,45)$. In Oroya fever, the acute form of bartonellosis (an infection transmitted by the sandfly), organisms can be isolated from the blood of patients when blood samples are subcultured to medium containing rabbit blood and incubated at 28 to $30^{\circ} \mathrm{C}(19)$. R. quintana (transmitted by the louse) has been easily isolated for as long as 1 month after the illness from the blood of patients with trench fever and from one volunteer who was inoculated experimentally by Varela and associates (44). Koehler and coworkers (18) have reported exposure to possible vectors in two of their patients with bacillary angiomatosis; one patient whose samples grew $R$. quintana owned a pet rat and the patient whose samples grew $R$. henselae owned cats. The serological data reported by Regnery and colleagues (29) implicate Rochalimaea species as a possible etiologic agent of cat scratch disease (30), and $R$. henselae has been cultured from lymph nodes in two patients (53) and from the blood of a domestic cat (29). However, the etiology of cat scratch disease remains controversial. The proposed etiologic agent was first reported to be a bacterium (14) that subsequently was named Afipia felis (5); it has been detected by PCR in a lymph node of a patient with the disease (9) and produced a serological response in another patient (13). On balance, the present data indicate that $R$. henselae and possibly other Rochalimaea species may cause most cases of cat scratch disease, but a possible role for $A$. felis has not been ruled out, nor has the possibility of dual infection.

Our patient represents the first reported case of infection caused by $R$. elizabethae sp. nov. and the first case of

TABLE 4. 16S rRNA similarity matrix ${ }^{a}$

\begin{tabular}{lccccc}
\hline & \multicolumn{5}{c}{$\%$ Similarity } \\
\cline { 2 - 6 } \multicolumn{1}{c}{ Organism } & $\begin{array}{c}R . \\
\text { vinsonii }\end{array}$ & $\begin{array}{c}R . \\
\text { henselae }\end{array}$ & $\begin{array}{c}R . \\
\text { quintana }\end{array}$ & $\begin{array}{c}R . \\
\text { elizabethae }\end{array}$ & $\begin{array}{c}B . \\
\text { bacilliformis }\end{array}$ \\
\hline R. vinsonii & & & & & \\
R. henselae & 99.6 & & & & \\
R. quintana & 99.1 & 99.4 & & & \\
R. elizabethae & 99.4 & 99.2 & 98.9 & & \\
B. bacilliformis & 98.5 & 98.6 & 98.6 & 98.4 & \\
\hline
\end{tabular}

${ }^{a}$ Numbers represent percent similarity corrected for multiple base changes by the method of Jukes and Cantor (17). endocarditis caused by a Rochalimaea species. We can only speculate why this infection developed. The patient had no known exposure to animals or insect vectors, was not apparently immunosuppressed, and was HIV antibody negative, in contrast to most patients reported to have bacillary angiomatosis or bacteremia caused by $R$. henselae $(37,38$, 52). He did not have any predisposition to endocarditis, such as cardiac valvular abnormalities. A risk factor for bacteremia was his poor dentition and, possibly, intestinal strongyloidiasis, an infection known to be associated with a predisposition to bacteremia resulting from organisms in the stools of patients with overwhelming infestations (36). Until the ecological niche of $R$. elizabethae is identified, it cannot be determined whether our patient's parasitic infection caused by $S$. stercoralis played a part in the acquisition of this organism.

Rapid, direct identification of Rochalimaea-like organisms in blood or tissue would facilitate appropriate treatment for future cases because blood cultures are likely to remain negative for weeks. Cure of endocarditis depends on the use of appropriate bactericidal agents for a prolonged time period, and antimicrobial therapy for culture-negative endocarditis generally has consisted of a combination of ampicil-

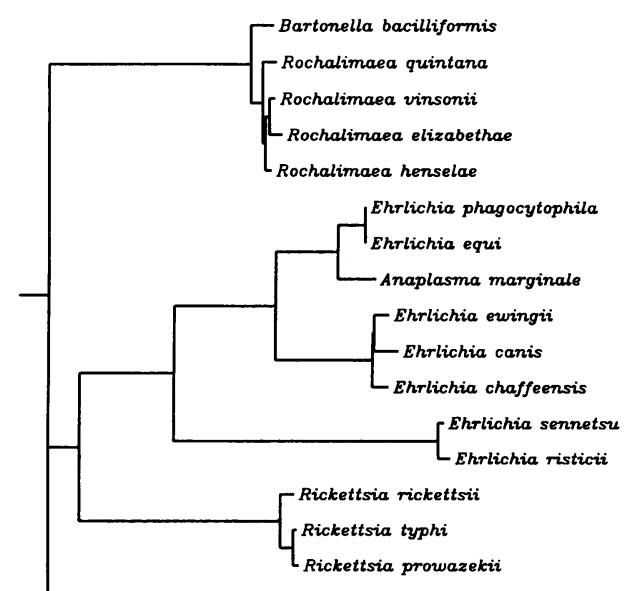

Anacystis nidulans

FIG. 4. Phylogenetic tree for members of the order Rickettsiales, with $A$. nidulans as the outgroup. The tree was inferred from $16 \mathrm{~S}$ rRNA similarity data by the neighbor-joining method (34). The bar represents a $5 \%$ difference in nucleotide sequence. 
lin or vancomycin and gentamicin. When given intravenously for 2 to 6 weeks, this regimen produces cure rates of $92 \%$ in patients who become afebrile (43). This therapy, however, may not be ideal for patients with Rochalimaea infections, even though the organisms appear to be susceptible to most antibiotics. Our patient was cured with a combination of medical and surgical therapy, and $R$. elizabethae sp. nov. was not recovered from blood cultures obtained after 2 days of treatment with nafcillin and gentamicin therapy or from the cardiac valve removed after 18 days of therapy, despite the presence of organisms on pathologic examination. This suggests that the $R$. elizabethae sp. nov. was susceptible in vivo to either nafcillin or gentamicin or both of these agents, but the ideal therapy is not known.

As laboratories become aware of the growth characteristics of Rochalimaea species and physicians better understand the illnesses caused by these pathogens, it is likely that more cases will be recognized. With an increase in the frequency of detection, more in vitro information about antimicrobial susceptibility and in vivo data about clinical risk factors for infection will emerge to help clinicians correctly diagnose and treat patients infected with these organisms.

Description of $R$. elizabethae sp. nov. $R$. elizabethae (e.liz' a.beth.e.a. N.L. fem. adj. elizabethae), named after Saint Elizabeth's Hospital, Brighton, Mass., where the organism was isolated. Biochemical reactions are given in Table 1. Its closest phenotypic relative is $R$. henselae, from which it appears to be differentiated by incomplete hemolysis on rabbit blood agar. It is presumed to be pathogenic for humans.

Description of the type strain. The type strain of $R$. elizabethae is F9251 (=B91-002005 = ATCC 49927). It shares all the characteristics of the species. The GC content of DNA was $41.0 \mathrm{~mol} \%$. It was isolated from the blood of a man with endocarditis.

\section{ACKNOWLEDGMENTS}

We are grateful to Laura LaFleur Nocia and Chandrakant Mepani for help in the isolation and initial characterization of F9251, Renée Robillard for editorial assistance, and Karen Amidon-Coelho for typing the manuscript. We are indebted to Thomas Ozro MacAdoo, associate professor emeritus of Greek and Latin, Virginia Polytechnic Institute and State University, Blacksburg, for advice on naming the new species.

\section{ADDENDUM IN PROOF}

DNA from the paraffin-embedded tissue block of the patient's heart valve was amplified using Rochalimaea genus-specific 16S RNA primers and was positive (personal communication, B. Swaminathan, Centers for Disease Control).

\section{REFERENCES}

1. Anderson, B. E., J. E. Dawson, D. C. Jones, and K. H. Wilson. 1991. Ehrlichia chaffeensis, a new species associated with human ehrlichiosis. J. Clin. Microbiol. 29:2838-2842.

2. Baker, J. A. 1946. A rickettsial infection in Canadian voles. J. Exp. Med. 84:37-51.

3. Bauer, A. W., W. M. M. Kirby, J. C. Sherris, and M. Turck. 1966. Antibiotic susceptibility testing by a standardized single disk method. Am. J. Clin. Pathol. 45:493-496.

4. Birtles, R. J., T. G. Harrison, N. K. Fry, N. A. Saunders, and A. G. Taylor. 1991. Taxonomic considerations of Bartonella bacilliformis based on phylogenetic and phenotypic character- istics. FEMS Microbiol. Lett. 83:187-192.

5. Brenner, D. J., D. G. Hollis, C. W. Moss, C. K. English, G. S. Hall, J. Vincent, J. Radosevic, K. A. Birkness, W. F. Bibb, F. D. Quinn, B. Swaminathan, R. E. Weaver, N. W. Reeves, S. P. O'Connor, P. S. Hayes, F. C. Tenover, A. G. Steigerwalt, B. A. Perkins, M. I. Daneshvar, B. C. Hill, J. A. Washington, T. C. Woods, S. B. Hunter, T. L. Hadfield, G. W. Ajello, A. F. Kaufmann, D. J. Wear, and J. D. Wenger. 1991. Proposal of Afipia, gen. nov., with Afipia felis sp. nov. (formerly the cat scratch disease bacillus), Afipia clevelandensis sp. nov. (formerly the Cleveland Clinic Foundation strain), Afipia broomeae sp. nov., and three unnamed genospecies. J. Clin. Microbiol. 29: 2450-2460.

6. Brenner, D. J., A. C. McWhorter, J. K. Leete Knutson, and A. G. Steigerwalt. 1982. Escherichia vulneris: a new species of Enterobacteriaceae associated with human wounds. J. Clin. Microbiol. 15:1133-1140.

7. Brenner, D. J., S. P. O'Connor, D. G. Hollis, R. E. Weaver, and A. G. Steigerwalt. 1991. Molecular characterization and proposal of a neotype strain for Bartonella bacilliformis. J. Clin. Microbiol. 29:1299-1302.

8. Brosius, J., T. J. Dull, D. D. Sleeter, and H. F. Noller. 1981. Gene organization and primary structure of a ribosomal RNA operon from Escherichia coli. J. Mol. Biol. 148:107-127.

9. Case Records of the Massachusetts General Hospital. 1992. Case 22-1992. N. Engl. J. Med. 326:1480-1489.

10. Clark, W. A., D. G. Hollis, R. E. Weaver, and P. Riley. 1984. Identification of unusual pathogenic gram-negative aerobic and facultatively anaerobic bacteria. Centers for Disease Control, Atlanta.

11. De Ley, J. 1970. Reexamination of the association between melting point, buoyant densities, and chemical base composition of deoxyribonucleic acid. J. Bacteriol. 101:738-754.

12. Devereux, J., P. Haeberli, and O. Smithies. 1984. A comprehensive set of sequence analysis programs for the VAX. Nucleic Acids Res. 12:387-395.

13. Drancourt, M., A. Donnet, J. Pelletier, and D. Raoult. 1992. Acute meningoencephalitis associated with seroconversion to "Afipia felis." Lancet 340:558.

14. English, C. K., D. J. Wear, A. M. Margileth, C. R. Lissner, and G. P. Walsh. 1988. Cat-scratch disease. Isolation and culture of the bacterial agent. JAMA 259:1347-1352.

15. Felsenstein, J. 1989. PHYLIP-Phylogeny inference package (version 3.2). Cladistics 5:164-166.

16. Hultman, T., S. Stahl, E. Hornes, and M. Uhlen. 1989. Direct solid phase sequencing of genomic and plasmid DNA using magnetic beads as solid support. Nucleic Acids Res. 17:49374946.

17. Jukes, T. H., and C. R. Cantor. 1969. Evolution of protein molecules, p. 21-132. In H. N. Munro (ed.), Mammalian protein metabolism, vol. 3. Academic Press, Inc., New York.

18. Koehler, J. E., F. D. Quinn, T. G. Berger, P. E. LeBoit, and J. W. Tappero. 1992. Isolation of Rochalimaea species from cutaneous and osseous lesions of bacillary angiomatosis. N. Engl. J. Med. 325:1625-1631.

19. Kreier, J. P., and M. Ristic. 1981. The biology of hemotrophic bacteria. Annu. Rev. Microbiol. 35:325-338.

20. Krieg, A. 1961. Grundlagen der Insektenpathologie; VirenRickettsien-und Bakterien-Infektionen. Steinkopff, Darmstadt, Germany.

21. Lennette, E. H., A. Balows, W. J. Hausler, Jr., and H. J. Shadomy (ed.). 1985. Manual of clinical microbiology, 4th ed. American Society for Microbiology, Washington, D.C.

22. Marmur, J., and P. Doty. 1962. Determination of the base composition of deoxyribonucleic acid from its thermal denaturation temperature. J. Mol. Biol. 5:109-118.

23. Moss, C. W., and M. A. Lambert-Fair. 1989. Location of double-bonds in monounsaturated fatty acids of Campylobacter cryaerophila with dimethyl disulfide derivatives and combined gas chromatography-mass spectrometry. J. Clin. Microbiol. 27:1467-1470.

24. Murray, R. G. E., D. J. Brenner, R. R. Colwell, P. De Vos, M. Goodfellow, P. A. D. Grimont, N. Pfennig, E. Stackebrandt, and 
G. A. Zavarzin. 1990. Report of the ad hoc advisory committee on approaches to taxonomy within the proteobacteria. Int. J. Syst. Bacteriol. 40:213-215.

25. Noguchi, H. 1926. Etiology of Oroya fever. V. The experimental transmission of Bartonella bacilliformis by ticks (Dermacentor andersoni). J. Exp. Med. 23:729-734.

26. O'Connor, S. P., M. Dorsch, A. G. Steigerwalt, D. J. Brenner, and E. Stackebrandt. 1991. 16S rRNA sequences of Bartonella bacilliformis and cat scratch disease bacillus reveal phylogenetic relationships with the alpha-2 subgroup of the class Proteobacteria. J. Clin. Microbiol. 29:2144-2150.

27. Perkocha, L. A., S. M. Geaghan, T. S. Benedict Yen, S. L. Nishimura, S. P. Chan, R. Garcia-Kennedy, G. Honda, A. C. Stolofi, H. Z. Klein, R. L. Goldman, S. Van Meter, L. D. Ferrell, and P. E. LeBoit. 1990. Clinical and pathological features of bacillary peliosis hepatis in association with human immunodeficiency virus infection. N. Engl. J. Med. 323:1581-1586.

28. Regnery, R. L., B. E. Anderson, J. E. Clarridge III, M. C. Rodriquez-Barradas, D. C. Jones, and J. H. Carr. 1991. Characterization of a novel Rochalimaea species, $R$. henselae sp. nov., isolated from blood of a febrile, human immunodeficiency virus-positive patient. J. Clin. Microbiol. 30:265-274.

29. Regnery, R. L., M. Martin, and J. Olson. 1992. Naturally occurring "Rochalimaea henselae" infection in a domestic cat. Lancet 340:557-558.

30. Regnery, R. L., J. G. Olson, B. A. Perkins, and W. Bibb. 1992. Serological response to "Rochalimaea henselae" antigen in suspected cat-scratch disease. Lancet 339:1443-1445.

31. Relman, D. A., P. W. Lepp, K. N. Sadler, and T. M. Schmidt. 1992. Phylogenetic relationships among the agent of bacillary angiomatosis Bartonella bacilliformis, and other alpha-proteobacteria. Mol. Microbiol. 6:1801-1807.

32. Relman, D. A., J. S. Loutit, T. M. Schmidt, S. Falkow, and L. S. Tompkins. 1990. The agent of bacillary angiomatosis: an approach to the identification of uncultured pathogens. N. Engl. J. Med. 323:1573-1580.

33. Relman, D. A., L. A. Perkocha, K. N. Min, D. F. Welch, P. E. LeBoit, and L. N. Slater. 1991. The organism causing bacillary angiomatosis, peliosis hepatitis, and fever and bacteremia in immunocompromised patients. N. Engl. J. Med. 324:1544.

34. Saitou, N., and M. Nei. 1987. The neighbor-joining method: a new method for reconstructing phylogenetic trees. Mol. Biol. Evol. 4:406-425.

35. Schmincke, A. 1917. Histopathologischer Befund in Roseolen der Haut bei wolhynischem Feiber. Muench. Med. Wochschr. 64:91.

36. Scowden, E. B., W. Schafiner, and W. J. Stone. 1978. Overwhelming strongyloidiasis; an unappreciated opportunistic infection. Medicine 6:527-544.

37. Slater, L. N., D. F. Welch, D. Hensel, and D. W. Coody. 1990. A newly recognized fastidious gram-negative pathogen as a cause of fever and bacteremia. N. Engl. J. Med. 323:1587-1593.

38. Slater, L. N., D. F. Welch, and K. Min. 1992. Rochalimaea henselae causes bacillary angiomatosis and peliosis hepatis.
Arch. Intern. Med. 152:602-606.

39. Stackebrandt, E., and O. Charfreitag. 1990. Partial 16S rRNA primary structure of five Actinomycetes species: phylogenetic implications and development of an Actinomycetes israelii specific oligonucleotide probe. J. Gen. Microbiol. 136:37-43.

40. Tomioka, N., and M. Sugiura. 1983. The complete nucleotide sequence of a 16S ribosomal RNA gene from a blue-green alga, Anacystis nidulans. Mol. Gen. Genet. 191:46-50.

41. Tunkel, A. R., and D. Kay. 1992. Endocarditis with negative blood cultures. N. Engl. J. Med. 326:1215-1218.

42. Tyeryar, F. J., Jr., E. Weiss, D. B. Millar, F. M. Bozeman, and R. A. Ormsbee. 1973. DNA composition of rickettsiae. Science 180:415-417.

43. Van Scoy, R. E. 1982. Culture-negative endocarditis. Mayo Clin. Proc. 57:149-154.

44. Varela, G. J., W. Vinson, and C. Molina-Pasquel. 1969. Trench fever. II. Propagation of Rickettsia quintana on cell-free medium from the blood of two patients. Am. J. Trop. Med. Hyg. 18:708-712.

45. Vinson, J. W. 1966. In vitro cultivation of the rickettsial agent of trench fever. Bull. W.H.O. 35:155-164.

46. Washington, J. A. 1982 . The role of the microbiology laboratory in the diagnosis and antimicrobial treatment of infective endocarditis. Mayo Clin. Proc. 57:22-32.

47. Wayne, L. G., D. J. Brenner, R. R. Colwell, P. A. D. Grimont, O. Kandler, M. I. Krichevsky, L. H. Moore, W. E. C. Moore, R. G. E. Murray, E. Stackebrandt, M. P. Starr, and H. G. Trüper. 1987. Report of the ad hoc committee on reconciliation of approaches to bacterial systematics. Int. J. Syst. Bacteriol. 37:463-464.

48. Weisburg, W. G., S. M. Barns, D. A. Pelletier, and D. J. Lane. 1991. 16S ribosomal DNA amplification for phylogenetic study. J. Bacteriol. 173:697-703.

49. Weisburg, W. G., M. E. Dobsin, J. E. Samuel, G. A. Dasch, L. P. Malliva, O. Baga, L. Mandelco, J. E. Sechrest, E. Weiss, and C. R. Woese. 1989. Phylogenetic diversity of the rickettsiae. J. Bacteriol. 171:4202-4206.

50. Weiss, E., and G. A. Dasch. 1982. Differential characteristics of strains of Rochalimaea: Rochalimaea vinsonii sp. nov., the Canadian vole agent. Int. J. Syst. Bacteriol. 32:305-314.

51. Weiss, E., G. A. Dasch, G. R. Woodman, and J. C. Williams. 1978. Vole agent identified as a strain of the trench fever rickettsia, Rochalimaea quintana. Infect. Immun. 19:10131020.

52. Welch, D. F., D. A. Pickett, L. N. Slater, A. G. Steigerwalt, and D. J. Brenner. 1992. Rochalimaea henselae sp. nov., a cause of septicemia, bacillary angiomatosis, and parenchymal bacillary peliosis. J. Clin. Microbiol. 30:275-280.

53. Wong, M. W., and M. J. Dolan. 1992. Rochalimaea henselae sp. nov. presenting as painful unilateral adenopathy in two previously healthy patients, abstr. D-175, p. 125. Abstr. 92nd Annu. Meet. Am. Soc. Microbiol. 1992. American Society for Microbiology, Washington, D.C. 